\title{
Результаты радиочастотной катетерной деструкции у пациентов с длительно персистирующей формой фибрилляции предсердий
}

\author{
Доронин А.В. ${ }^{1}$ Мешкова Н.С. ${ }^{2}$ \\ ${ }^{1}$ Национальная медицинская академия последипломного образования имени П. Л. Шупика, Киев, Україна \\ 2 ГУ «Научно-практический медицинский центр детской кардиологии и кардиохирургии МЗ Украины», Киев, Україна
}

\begin{abstract}
Резюме. Результаты катетерного лечения непароксизмальных форм фибрилляции предсердий (ФП) хуже, чем пароксизмальных. В статье представлены результаты радиочастотной катетерной деструкции длительно персистирующей формы ФП у 47 последовательных пациентов, которым было выполнено 57 процедур, что составило 1,2 процедуры на пациента.
\end{abstract}

Большинство процедур выполнено без применения навигационных систем с использованием электродов без функции охлаждения с дистальным электродом 4 мм.

После первой процедуры в течение 1 года синусовый ритм удерживался у $27(57,4 \%)$ пациентов. С учетом повторных процедур синусовый ритм в течение 1 года был у 35 (74,5\%) пациентов, из них антиаритмические препараты принимали 8 (22,9\%) больных. После последней процедуры удалось проследить судьбу $42(89,4 \%)$ пациентов. Средний период наблюдения составил $2,6 \pm 1,9$ года. Синусовый ритм сохранился у $19(45,2 \%)$ пациентов, из них антиаритмическую терапию получали $11(57,9 \%)$.

Таким образом, представленная методика является достаточно эффективной при длительно персистирующей форме ФП.

Ключевые слова: фибрилляция предсердий, катетерная деструкция, фрагментированные электрограммы.

В настоящее время антральная изоляция легочных вен является основополагающим элементом катетерной деструкции фибрилляции предсердий (ФП) [1]. В то время как катетерное лечение пароксизмальной формы ФП дает хорошие результаты, лечение персистирующих и длительно персистирующих форм ФП остается проблемным [2]. Катетерная деструкция симптоматической длительно персистирующей формы ФП относится к IIb классу рекомендаций [3].

В последние годы появились работы, показывающие отсутствие эффекта от применения различных методик, дополняющих изоляцию легочных вен. Практически все эти методики относятся к IIb классу рекомендаций [3]. Также сообщается об успешном применении методик, вообще не предусматривающих изоляцию легочных вен [4]. С другой стороны, многие считают, что одной изоляции легочных вен недостаточно для эффективного устранения персистирующей формы ФП [5].

Было продемонстрировано, что избыточное повреждение тканей предсердий при деструкции ФП может приводить к формированию больших участков фиброза и созданию субстрата для предсердных аритмий, понижая тем самым эффективность процедуры [6]. Многие авторы сохранение синусового ритма с использованием антиаритмических препаратов также считают положительным результатом деструкции [7].
Несмотря на применение различных методик, эффективность катетерной деструкции персистирующей формы ФП после одной процедуры составляет 20$60 \%$. После проведения повторных процедур $(1,3-2,3$ на 1 пациента) ритм с применением или без применения антиаритмической терапии удается контролировать у 72-79\% пациентов [2].

Цель работы - проанализировать собственный опыт выполнения радиочастотной катетерной деструкции у пациентов с длительно персистирующей формой ФП.

Материалы и методы. В ГУ «Научно-практический медицинский центр детской кардиологии и кардиохирургии МЗ Украины» в период с 01.2014 г. по 09.2017 г. у 47 последовательных пациентов с длительно персистирующей ФП произведено 57 катетерных деструкций. Результаты в течение года после последней катетерной деструкции удалось проследить у всех пациентов. В средний период наблюдения $2,6 \pm 1,9$ года (от 1,2 до 4 лет) после последней процедуры проследить удалось судьбу $42(89,4 \%)$ пациентов.

В группе было 16 (34,0\%) женщин и $31(66,0 \%)$ мужчина. Средний возраст пациентов составил $55,6 \pm 8,1$ года (от 35 до 75 лет).

У $25(53,2)$ пациентов диагностирована гипертоническая болезнь, у $5(10,6 \%)$ - заболевания щитовидной железы, у $6(12,8 \%)$ пациентов - ИБС, у $3(6,4 \%)$ выполнено стентирование коронарных артерий, 2 (4,3\%) 
перенесли инсульт, 5 (10,6\%) имели сахарный диабет, $1(2,1 \%)$ пациент имел хроническое обструктивное заболевание легких, $1(2,1 \%)$ - дефект межпредсердной перегородки с легочной гипертензией, $1(2,1 \%)$ - аномалию Эбштейна, у 1 (2,1\%) было удалено левое легкое, у $1(2,1 \%)$ имплантирован электрокардиостимулятор по поводу слабости синусового узла. Фракция выброса менее $50 \%$ (минимально - 25\%) зафиксирована у $9(19,1 \%)$ больных.

Всем пациентам перед процедурой назначались антикоагулянты в течение четырех недель. Антиаритмическая и антикоагулянтная терапия не прекращалась.

Процедура производилась под интубационным наркозом. Выполнялась двойная транссептальная пункция под контролем чреспищеводной эхокардиографии. Использовался деструкционный электрод без функции охлаждения с дистальным электродом 4 мм. Навигационная система применялась у одного пациента при выполнении третьей процедуры. Деструкционный электрод извлекался и протирался влажной салфеткой после каждых 15-20 аппликаций. После изоляции легочных вен наносились аппликации в местах регистрации фрагментированных электрограмм в левом предсердии на фоне в/в капельного введения 300 мг кордарона. В правом предсердии наносились по 3 аппликации в устьях верхней и нижней полых вен. Выполнялась линия аппликаций по задней стенке правого предсердия между полыми венами. Синусовый ритм восстанавливался с использованием ЭИТ. При повторных процедурах операция проводилась по аналогичной методике. При выполнении третьей операции добавлялись линии между верхними и нижними легочными венами и линия между устьем левой нижней легочной вены и кольцом митрального клапана.

Мощность воздействия составила 35 Ватт, температура $-55^{\circ} \mathrm{C}$, время аппликации -40 секунд.

В послеоперационном периоде больные наблюдались минимум 2 раза (через 1 и 3 месяца после процедуры) с записью холтеровской и стандартной ЭКГ. Далее холтеровская и стандартная ЭКГ проводились через 6 месяцев и через 1 год, в дальнейшем - по показаниям. Пациенты были ознакомлены с методами контроля сердечного ритма. Большинство данных в отдаленном периоде были получены в телефонном режиме.

Результаты и обсуждение. Среднее время рентгенэкспозиции составило $28,2 \pm 7,4$ мин. Количество ап-

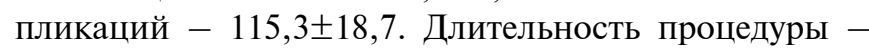
$2,4 \pm 0,5$ часа. Отмечалась тенденция к уменьшению рентген-экспозиции и длительности процедуры по мере накопления опыта.

После первой процедуры в течение 1 года синусовый ритм удерживался у $27(57,4 \%)$ пациентов. С учетом повторных процедур синусовый ритм в течение 1 года был у 35 (74,5\%) пациентов, из них антиаритмические препараты принимали 8 (22,9\%) больных: 4 па- циента принимали кордарон, 3 - $\beta$-адреноблокаторы, 1 - соталол. Еще у 7 (14,9\%) пациентов наблюдалась пароксизмальная форма ФП, из них 3 пациента принимали $\beta$-адреноблокаторы, 2 - кордарон, у 2 антиаритмическая терапия применялась эпизодически. Таким образом, синусовый ритм или переход в пароксизмальную форму ФП наблюдался у $42(89,4 \%)$ больных.

После последней процедуры удалось проследить судьбу у $42(89,4 \%)$ пациентов. Средний период наблюдения составил $2,6 \pm 1,9$ года. Один пациент умер от инсульта на фоне синусового ритма во время гипертонического криза через 2,6 года после катетерной деструкции. Синусовый ритм сохранился у $19(45,2 \%)$ пациентов, из них антиаритмическую терапию получали 11 (57,9\%): 8 - кордарон, 1 - соталол, 1 - флекаинид и $1-\beta$-адреноблокаторы. Еще у $13(31,0 \%)$ пациентов наблюдалась пароксизмальная форма ФП: 6 пациентов получали бисопролол, 3 - кордарон, у 4 регулярная антиаритмическая терапия не применялась. Синусовый ритм или переход в пароксизмальную форму ФП наблюдался у $32(76,2 \%)$ больных. При субъективной оценке своего состояния значительное улучшение отмечали $14(33,3 \%)$ пациентов, улучшение - $23(54,8 \%)$, не отмечали улучшения $5(11,9 \%)$ пациентов.

У большинства больных с рецидивом аритмии наблюдалась ФП, у 1 (2,1\%) было типичное трепетание предсердий (ТП), у другого - левостороннее трепетание предсердий. Трепетания были устранены при проведении повторной процедуры.

Осложнение возникло при проведении 1 (1,8\%) процедуры. Это была тампонада перикарда, которая разрешилась путем перикардиоцентеза.

Изоляцию легочных вен мы делали по краю электрода типа «Lasso», который находился в устье легочной вены. В этой зоне стенка предсердий относительно тонкая. Электроды 4 мм без функции охлаждения делают менее глубокое повреждение по сравнению с охлаждаемыми электродами, но такое повреждение вполне достаточно для изоляции легочных вен.

Изоляция легочных вен дополнялась аппликациями в местах регистрации «фрагментированных электрограмм». Поскольку мы не делали линий аппликаций, нам не нужно было добиваться трансмуральности повреждения. С другой стороны, мы не боялись повредить структуры, прилегающие к сердцу, либо вызвать значимый стеноз легочных вен. Наши теоретические рассуждения подтверждаются низким числом осложнений, не превышающим значения, приводимые в литературе [8].

Редкое возникновение трепетаний предсердий после проведения процедуры подтверждает факт, что мы не делали избыточного повреждения тканей предсердий и не создавали субстрат для возникновения аритмий.

Устранение аритмии не подтверждалось имплантацией систем для фиксации нарушений ритма, однако 
прекращение длительно существующей формы ФП фиксируется относительно легко.

\section{Выводы}

- Изоляция устьев легочных вен с дополнительным нанесением аппликаций в местах регистрации «фрагментированных электрограмм» у пациентов с длительно персистирующей формой ФП эффективна и безопасна.

- Применение электродов без функции охлаждения с дистальным электродом 4 мм не увеличивает число осложнений у данной группы пациентов.

\section{Список использованных источников}

1. Teunissen C, Clappers N, Hassink RJ, van der Heijden JF, Wittkampf FH, Loh P. A decade of atrial fibrillation ablation Shifts in patient characteristics and procedural outcomes. Neth Heart J. 2017;25(10):559-66. https://doi. org/10.1007/s12471-017-1019-7

2. Pak H-N. Catheter Ablation of Long-standing Persistent Atrial Fibrillation: a Reckless Challenge or a Way to Real Cure? Korean Circ J. 2019 Feb;49(2): 134-45. https://doi. org/10.4070/kcj.2018.0418

3. Calkins H, Hindricks G, Cappato R, Kim Y-H, Saad EB, Aguinaga L, et all. 2017 HRS/EHRA/ECAS/APHRS/ SOLAECE expert consensus statement on catheter and surgical ablation of atrial fibrillation. Heart Rhythm. 2017 Oct;14(10):e275-e444. https://doi.org/10.1016/j. hrthm.2017.05.012
4. Oketani N, Seitz J, Salazar M, Pisapia A, Kalifa J, Smit $\mathrm{JJ}$, et al. Ablation of complex fractionated electrograms is useful for catheter ablation of persistent atrial fibrillation: Protagonist point of view. Heart Rhythm. 2016 Oct;13(10):2098-100. https://doi.org/10.1016/j. hrthm.2016.06.036

5. Tilz RR, Rillig A, Thum AM, Arya A, Wohlmuth P, Metzner A, et al. Catheter ablation of long-standing persistent atrial fibrillation: 5-year outcomes of the Hamburg Sequential Ablation Strategy. J Am CollCardiol. 2012;60(19):1921-9. https://doi.org/10.1016/j.jacc.2012.04.060

6. Kim TH, Uhm JS, Kim JY, Joung B, Lee MH, Pak HN. Does Additional Electrogram-Guided Ablation After Linear Ablation Reduce Recurrence After Catheter Ablation for Longstanding Persistent Atrial Fibrillation? A Prospective Randomized Study. J Am Heart Assoc. 2017;6(2):e004811. https://doi.org/10.1161/JAHA.116.004811

7. Seitz J, Bars C, Thйodore G, Beurtheret S, Lellouche N, Bremondy M, et al. Wholly Patient-tailored Ablation of Atrial Fibrillation Guided by Spatio-Temporal Dispersion of Electrograms in the Absence of Pulmonary Veins Isolation. J Am Coll Cardiol. 2017 Jan;69(3):303-21. https://doi.org/10.1016/j.jacc.2016.10.065

8. Доронин АВ, Суслина ЮИ, Резник АС, Ханенова ВА, Марушко ЕЮ, Мешкова МС. Оценка безопасности проведения радиочастотной катетерной деструкции фибрилляции предсердий катетерами с дистальным электродом 4 мм без функции охлаждения. Вісник серцево-судинної хірургії. 2017;29(3):80-82.

\title{
Results of radio-frequency catheter ablations in patients with long-standing persistent atrial fibrillation
}

\author{
Doronin A. ${ }^{1}$, Meshkova M. $^{2}$ \\ ${ }^{1}$ Shupyk National Medical Academy of Postgraduate Education, Kyiv, Ukraine \\ 2 Ukrainian Children's Cardiac Center, Kyiv, Ukraine
}

Catheter treatment outcome in non-paroxysmal forms of atrial fibrillation (AF) is worse than that in paroxysmal forms. The search for optimal methods of AF catheter ablation is ongoing.

The objective is to analyze our own experience of radiofrequency catheter ablation in patients with long-standing persistent AF

Material and methods. The article presents the results of radiofrequency catheter ablations of long-standing persistent AF in 47 consecutive patients, who underwent 57 procedures, that is 1.2 procedures per patient. Most procedures were performed using non-irrigated catheters with a 4-mm distal electrode without using navigation systems.

Results and discussion. After the first procedure, sinus rhythm was maintained during 1 year in 27 (57.4\%) patients. Considering repeated procedures, 35 (74.5\%) patients were in sinus rhythm during 1 year, of which 8 (22.9\%) patients received antiarrhythmics. After the last procedure it was possible to follow up $42(89.4 \%)$ patients. The mean follow up period was $2.6 \pm 1.9$ years. Along with it, the sinus rhythm was preserved in $19(45.2 \%)$ patients, $11(57.9 \%)$ of them were on the antiarrhythmic therapy.

One $(2.1 \%)$ patient had typical atrial flutter $(\mathrm{AFl})$, and another one had left-sided AFl, which were ablated during the repeat procedures.

The one (1.8\%) procedure was complicated with pericardial tamponade, which was immediately resolved by pericardiocentesis.

The safety of using non-irrigated ablation catheters with a 4-mm distal electrode was confirmed by a low number of complications, not beyond the limits given in the literature.

Thus, this method of catheter ablation is quite effective and safe for long-standing persistent AF.

Keywords: atrial fibrillation, catheter ablation, fragmented electrograms. 


\title{
Результати радіочастотної катетерної деструкції у пацієнтів із тривало персистуючою формою фібриляції передсердь
}

\author{
Доронін О. В. ${ }^{1}$, Мешкова М. С. ${ }^{2}$ \\ ${ }^{1}$ Національна медична академія післядипломної освіти імені П. Л. Шупика (Київ) \\ 2 ДУ «Науково-практичний медичний центр дитячої кардіології та кардіохірургії МОЗ України» (Київ)
}

Результати катетерного лікування непароксизмальних форм фібриляції передсердь (ФП) гірші, ніж пароксизмальних. Триває пошук оптимальних методик їх катетерного усунення.

Мета роботи - проаналізувати власний досвід виконання радіочастотної катетерної деструкції у пацієнтів із тривало персистуючою формою ФП.

Матеріали та методи. У статті представлено результати радіочастотної катетерної деструкції тривало персистуючої форми ФП у 47 послідовних пацієнтів, яким було виконано 57 процедур, що становило 1,2 процедури на пацієнта.

Більшість процедур виконано без застосування навігаційних систем з використанням електродів без функції охолодження з дистальним електродом 4 мм.

Результати та обговорення. Після першої процедури протягом 1 року синусовий ритм утримувався у 27 (57,4\%) пацієнтів. 3 урахуванням повторних процедур синусовий ритм протягом 1 року був у 35 (74,5\%) пацієнтів, 3 них антиаритмічні препарати приймали 8 (22,9\%) хворих. Після останньої процедури вдалося простежити долю 42 $(89,4 \%)$ пацієнтів. Середній період спостереження становив $2,6 \pm 1,9$ року. Синусовий ритм зберігався у 19 (45,2\%) пацієнтів, з них антиаритмічну терапію отримували $11(57,9 \%)$.

В 1 (2,1\%) пацієнта було типове тріпотіння передсердь (ТП), в іншого - лівостороннє ТП, які були усунені при проведенні повторної процедури.

Ускладнення виникло при проведенні 1 (1,8\%) процедури - тампонади перикарда, яке усунули шляхом перикардіоцентезу.

Безпека використання деструкційних електродів з дистальним електродом 4 мм без функції охолодження підтверджується низьким числом ускладнень, що не перевищує показники, наведені в літературі.

Таким чином, представлена методика є досить ефективною та безпечною при тривало персистуючій формі ФП.

Ключові слова: фібриляція передсердь, катетерна деструкція, фрагментовані електрограми.

Стаття надійшла в редакцію 19.02.2019 